\title{
Corrigendum: Enantioselective synthesis of a chiral nitrogen-doped buckybowl
}

\author{
Qitao Tan, Shuhei Higashibayashi, Sangita Karanjit \& Hidehiro Sakurai
}

Nature Communications 3:891 doi: 10.1038/ncomms1896 (2012); Published 12 Jun 2012; Updated 8 Jan 2013.

In this Article, the space group for the crystal structure of compound 6 is noted as being triclinic P1. After re-examining the crystallographic data, however, we wish to revise the space group to monoclinic P21.

In the 'X-ray crystallography' section in Results, ' $9.8^{\circ}$ for $\mathrm{C} 1$ and $10.8^{\circ}$ for $\mathrm{C} 2$ ' should read ' $10.0^{\circ}$ for $\mathrm{C} 1$ and $10.7^{\circ}$ for $\mathrm{C} 2^{\prime}$. In the 'X-ray crystallography' section in Methods, 'Crystal data for $(C)-(-)$-6: triclinic, space group P1, $a=11.291(11), b=12.419(13), c=14.794$ (14) $\AA, \alpha=90.078(16), \beta=90.086(15), \gamma=101.952(18)^{\circ}, V=2,029.48 \AA^{3}, Z=4 ; R_{1}=0.0924 ; w R_{2}=0.1387$, Flack parameter $=0.09(9)$.' should read 'Crystal data for $(C)-(-)-6$ : monoclinic, space group P21, $a=11.295(12), b=14.798(15), c=12.421(14) \AA, \alpha=90.00$, $\beta=101.882(14), \gamma=90.00^{\circ}, V=2032(4) \AA^{3}, Z=4 ; R_{1}=0.0724 ; w R_{2}=0.1091$, Flack parameter $=0.05(8)$.’

The crystallographic data deposited in the Cambridge Crystallographic Data Centre have been replaced with the correct data, under the original accession code (CCDC-864009).

A corrected version of Fig. 3 appears below.

a

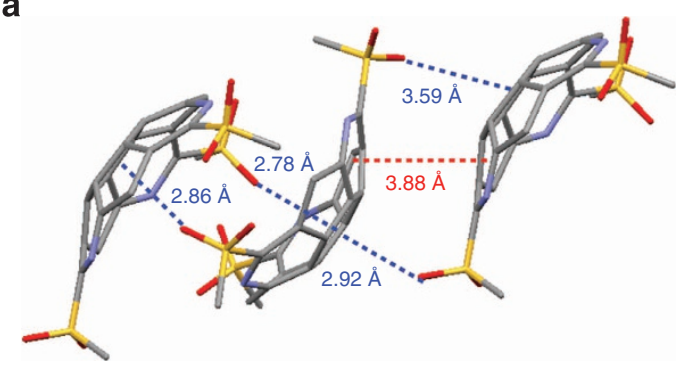

C

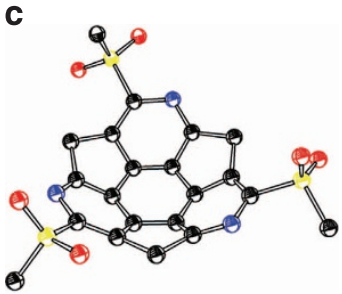

d

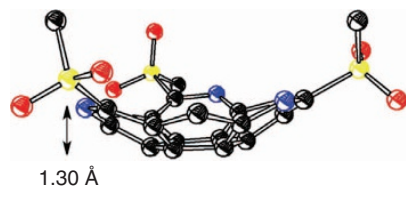

b

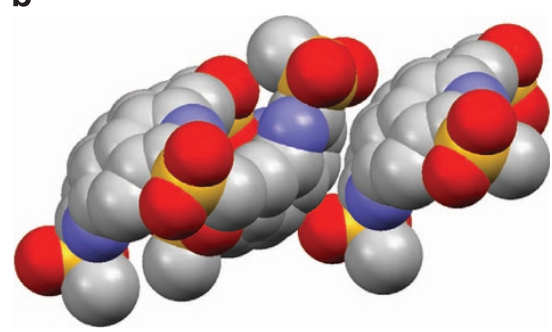

e
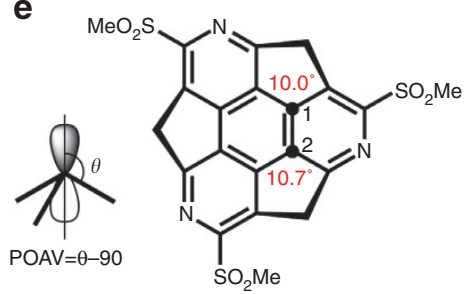

$\mathrm{POAV}=\theta-90 \quad \mathrm{SO}_{2} \mathrm{Me}$ 